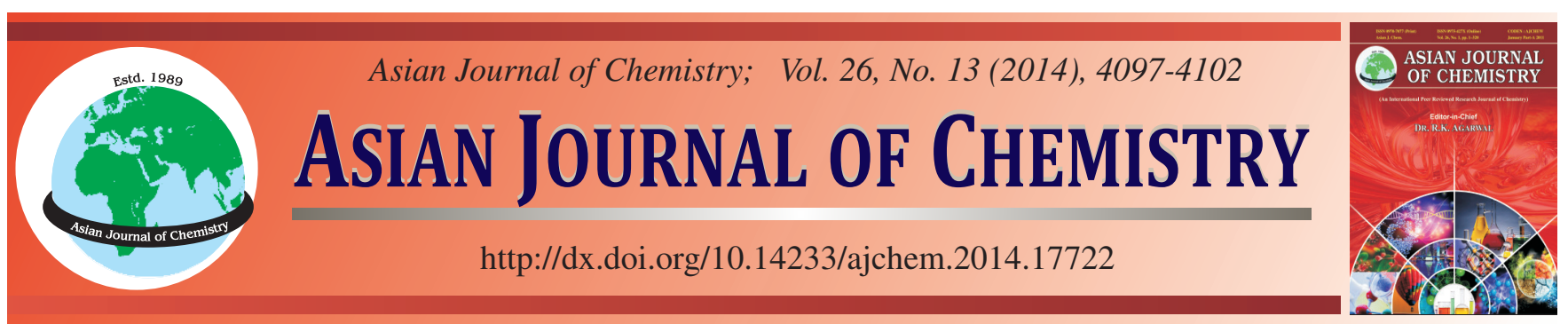

\title{
Photocatalytic and Reusability Studies of Novel ZnSe/Graphene Nanocomposites Synthesized via One Pot Hydrothermal Techniques $\uparrow$
}

\author{
Kefayat Ullah, Lei Zhu, Shu Ye, Sun-Bok Jo and Won-Chun OH*
}

Department of Advanced Materials Science \& Engineering, Hanseo University, Seosan-si, Chungnam-do 356-706, Republic of Korea

*Corresponding author: E-mail: chemul@naver.com

\begin{abstract}
Novel photocatalyst ZnSe/graphene nanocomposites were synthesized by facile hydrothermal techniques. The "as-prepared" nanocomposites are further characterized by various techniques such as X-ray diffraction (XRD), scanning electron microscopy (SEM) with an energy dispersive X-ray (EDX) analysis, transmission electron microscopy (TEM), UV-visible absorbance spectra analysis and Raman spectroscopic analysis. The photocatalytic activities of the composites were investigated by the degradation of Methylene orange and Rhodamine-B as a standard dyes. The photodegradation rates of organic dyes by the nanocomposites are found to be markedly high. Reused $\mathrm{ZnSe/}$ graphene showed very minute change in degradation efficiency which indicates excellent stability of our photocatalyst materials.
\end{abstract}

Keywords: Nanostructure, Chemical synthesis, X-Ray diffraction, Catalytic properties.

\section{INTRODUCTION}

Organic dyes are one of the main pollutants in waste water discharge by textile and photographic industries which disturbs the ecology and environment. Generally, the Rhodamine-B and Methylene orange are extensively used as a dyeing material in printing industries, the dissipation of these dyes causes several harmful diseases ${ }^{1,2}$. So far, it is an important issue to maintain a friendly ecosystem by removing these organic dyes from the polluted water. Recently several methods have been used to remove organic dyes such as Rhodamine-B and Methylene orange from waste water like coagulation, reverse osmosis and adsorbents ${ }^{3}$. Among them semiconductor photocatalysis is the most economical and easy way to decompose the organic pollutants to less harmful materials in assisting environment cleaning. Carbon nanostructures such as carbon nanotubes and graphene provide new opportunities to develop nanocomposites with unexpected photochemical and photo electrochemical properties ${ }^{4}$. Many strategies have been developed to synthesize graphene based nanocomposites for the modification of band gap and inhibition of intrinsic electron-hole pair recombination. For example $\mathrm{CdSe} / g r a p h e n e$ were synthesized via ultrasonication method and observed improved catalytic activity towards degradation of industrial dyes ${ }^{5}$. Similarly CdSe-graphene/ $/ \mathrm{TiO}_{2}$ was synthesized via hydrothermal process and high photonic effect was observed ${ }^{6}$. Cadmium sulfide
(CdS) microspheres decorated graphene (GR) nanocomposite (GR-CdS) was prepared by a facile hydrothermal approach and enhanced visible light catalytic activity were observed ${ }^{7}$. In this context, considerable interest has been very recently attracted to the incorporation of semiconductor materials $e . g$. $\mathrm{PtSe}_{2}{ }^{8}, \mathrm{CdTe}^{9}, \mathrm{NiO}^{10}$, to form graphene hybrid nanocomposites. Many approaches such as hydrothermal method ${ }^{11}$ sol-gel method $^{12}$ and microwave synthesis ${ }^{13}$ have been developed to anchor semiconductor materials on graphene sheet. Here in we report a facile way for the synthesis of $\mathrm{ZnSe} / \mathrm{graphene}$ via one pot hydrothermal assisted method. The photo catalytic activities of $\mathrm{ZnSe} /$ graphene hybrid material were tested by Rhodamine-B and Methylene orange as a model contaminant under visible light for comparison. The cyclic tests were also carried out to check the stability of our nanocomposites.

\section{EXPERIMENTAL}

Graphene oxide was prepared in the laboratory following the Hummer's-Offeman method. Zinc acetate dihydrated $\left.\left[\mathrm{Zn}\left(\mathrm{CH}_{3} \mathrm{COO}\right)_{2} \cdot 2 \mathrm{H}_{2} \mathrm{O}\right)\right]$ was used as a zinc source purchased from Kojima Chemical Co. Ltd., Japan. Selenium powder, Rhodamine$\mathrm{B}\left(\mathrm{C}_{28} \mathrm{H}_{31} \mathrm{CIN}_{2} \mathrm{O}_{3}\right)$ and Methylene orange $\left(\mathrm{C}_{14} \mathrm{H}_{14} \mathrm{~N}_{3} \mathrm{O}_{3} \mathrm{~S}\right)$ were used as organic model contaminant purchased from Samchun Pure Chemical Co. Ltd, Korea. In addition sodium sulphite $\left(\mathrm{Na}_{2} \mathrm{SO}_{3} \cdot 7 \mathrm{H}_{2} \mathrm{O}\right)$ was purchased from Dae-Jung Chemical 
and Metals Co. Ltd. Korea. All the chemicals were used as recevied and all experiments were carried out using distilled water.

Synthesis of $\mathrm{ZnSe}$ /graphene: For the preperation of selenium salt $2 \mathrm{~g}$ of anhydrous sodium sulphite $\left(\mathrm{Na}_{2} \mathrm{SO}_{3}\right)$ and $0.2 \mathrm{~g}$ of crude selenium powder ( $\mathrm{Se}$ ) were vigourously stirred in $100 \mathrm{~mL}$ of distilled water for $1 \mathrm{~h}$ to ensure the homogenous mixing. The selenium salt were ensured by the colour change after heat treating $\mathrm{Na}_{2} \mathrm{SO}_{3}$ and selenium powder to form a solution A. In the second step aproperiate amount of zinc acetate dihydrated and graphene oxide were mixed together and stirred for $0.5 \mathrm{~h}$ on magnetic stirrer to form a stable suspension B. A and $\mathrm{B}$ were mixed together and transferred into a Teflon-lined stainless steel autoclave $(300 \mathrm{~mL})$ and heat treated at $160{ }^{\circ} \mathrm{C}$ for $12 \mathrm{~h}$. The resultant solution was filtered and washed 3 times with distilled water and transferred into a dry oven for $6 \mathrm{~h}$ at $90{ }^{\circ} \mathrm{C}$. The obtained samples with different molar ratio were labeled as $\mathrm{ZnSe} / \mathrm{G} 1, \mathrm{ZnSe} / \mathrm{G} 2$ and $\mathrm{ZnSe} / \mathrm{G} 3$, respectively.

Photocatalytic activity: Photocatalytic activity of $\mathrm{ZnSe} /$ graphene synthesized via hydrothermal method was tested using Rhodamine-B and Methylene orange as an organic dyes. The initial and final concentrations of Rhodamine-B and Methylene orange solution were determined by measuring absorbance changes at their respective absorption maxima at 554 and $456 \mathrm{~nm}$. In each test, $10 \mathrm{mg}$ of catalytic sample were taken in $80 \mathrm{~mL}$ solution of organic dyes $\left(0.1 \mathrm{mg} \mathrm{mL}^{-1}\right)$. The solution was stirred on a magnetic stirrer at room temperature for several minutes moderately and kept in a dark for $2 \mathrm{~h}$ to maintain the adsorption/desorption equilibrium of the dye. After $2 \mathrm{~h}$ the solution was exposed to visible light source which was kept at $20 \mathrm{~cm}$ above the solution. Samples were collected after 30, 60, 90 and $120 \mathrm{~min}$ and centrifuged for $10 \mathrm{~min}$ instantly to remove the solid material from the solution for further analysis. The photocatalytic behaviours of the samples were analyzed by the absorbance spectrometry with UV/visible spectrophotometer (Optizen POP, Mecasys, Korea).

Characterizations: X-Ray patterns (XRD) measurements, were performed on a (Shimata XD-D1, Japan) with $\mathrm{CuK}_{\alpha}$ radiation at $40 \mathrm{kV}$ and $40 \mathrm{~mA}$. The scan rate was $0.02 \%$. The morphology characterization and structure analysis were carried out using scanning electronic microscopy (SEM) measurement on a (JSM-5200 JOEL, Japan). Transmission electron microscopy (TEM) measurement on a (TEM, JEOL, JEM2010, Japan). The primal composition analysis was performed by an energy dispersive spectrometer (EDS) attached to the (JSM-5200. Raman spectra of the samples were observed using a spectrometer (Jasco Model Name NRS-3100) having an excitation laser wavelength of $532.06 \mathrm{~nm}$. The decomposition kinetics for the photocatalytic activity was measured by using spectrometer (Optizen POP, Mecasys, Korea).

\section{RESULTS AND DISCUSSION}

Growth and characterization of $\mathrm{ZnSe} / g r a p h e n e$ nanocomposites: The XRD pattern of the $\mathrm{ZnSe}$ /graphene nanocomposites synthesized via hydrothermal method is shown in Fig. 1. The (002) diffraction peak of graphene is located at $26^{\circ}$ at $2 \theta$, the intensity of the peaks are very small as compared

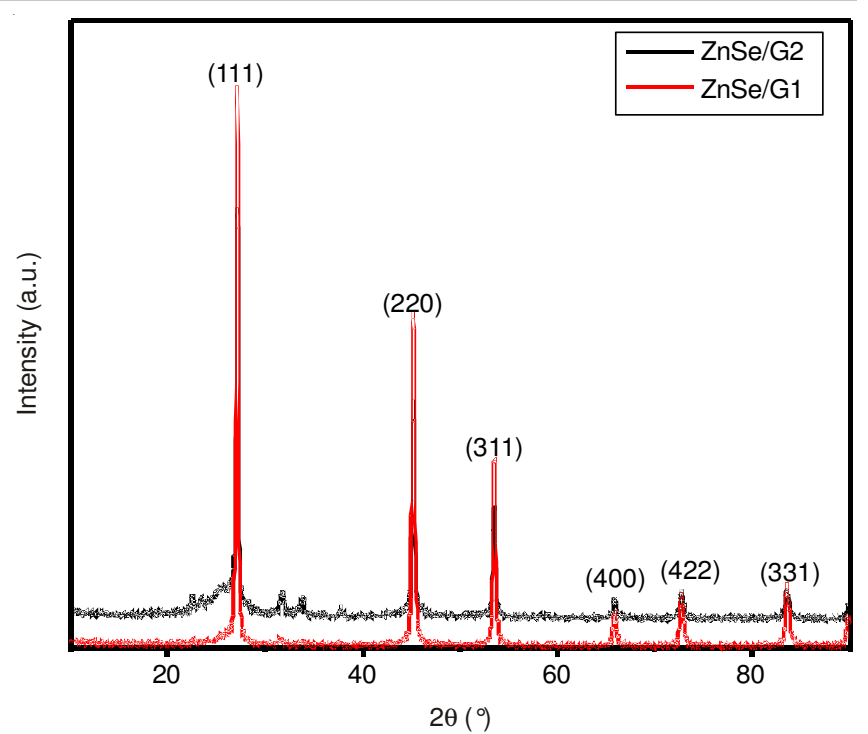

Fig. 1. XRD Pattern of ZnSe/graphene nanpcomposites

to $\mathrm{ZnSe}$ peaks. This suppression of the graphene peak confirms the development of $\mathrm{ZnSe}$ nanocrystals on graphene sheet. The crystalline ZnSe exhibit the characteristic (111), (220), (311), (400), (422), (331), reflections that correspond to hexagonal crystal phase having (JCPDS PDF\#: 00-065-9603). Peak intensity variations suggest that the lattice structure of $\mathrm{ZnSe}$ is distorted by the interaction with graphene. Addition of graphene into ZnSe resulted in the deterioration of crystallinity, as evidence by the decrease in the XRD peak intensity and variation in crystallite size ${ }^{14}$. The average particle size of $\mathrm{ZnSe}$ in $\mathrm{ZnSe}$ /graphene nanocomposites were calculated using scherrer equation based on the XRD peak broadening of (220) peak. The average particle sizes for the composites measured by using scherrer equation were in the range of 60-100 nm. The morphology of the $\mathrm{ZnSe} / \mathrm{G} 2$ nanocomposite synthesized via hydrothermal method is shown in Fig. 2(a-b). From the SEM image shown in Fig. 2(a), the flaky structure of graphene is clearly observed. During hydrothermal synthesis the graphene sheet is further broke off into thin small sheet type patterns ${ }^{15}$. Due to van der Waals interaction the graphene sheet tends to aggregate back to the graphite structure. Functionalizing with nanoparticles is helpful to overcome these interactions. In Fig. 2(b), it is worth noting the graphene sheet anchoring $\mathrm{ZnSe}$ nanoparticles using hydrothermal techniques. It can be seen from Fig. 2(b) that ZnSe nanoparticles occupy most of the available surface area of the graphene sheets, the nanoparticles are seen to be partially agglomerated. The elemental analysis of the composites was carried out by acquiring EDX spectra as shown in Fig. 2(c). The strong $\mathrm{K}_{\alpha}$ and $\mathrm{K}_{\beta}$ peaks from Se element appears at 11.2 and $2.4 \mathrm{KeV}$ with moderate $\mathrm{K}_{\alpha}$ peak from $\mathrm{O}$ element appear at $0.54 \mathrm{KeV}$. Fig. 2 also confirms the presence of $\mathrm{Zn}$ in the composite with the strong peaks at 8.3 $\mathrm{KeV}$. The elemental concentrations obtained from the EDX results are listed in Table-1. In which $\mathrm{C}$ element originates from the graphene sheet ${ }^{16}$. The nanoscale images of $\mathrm{ZnSe} / \mathrm{G} 2$ nanocomposite with different magnifications were taken by TEM. Fig. 3(a) large scale image of $\mathrm{ZnSe} / \mathrm{G} 2$ clearly demonstrates that $\mathrm{ZnSe}$ nanoparticles are dispersed throughout the surface of graphene sheets indicating an interaction 


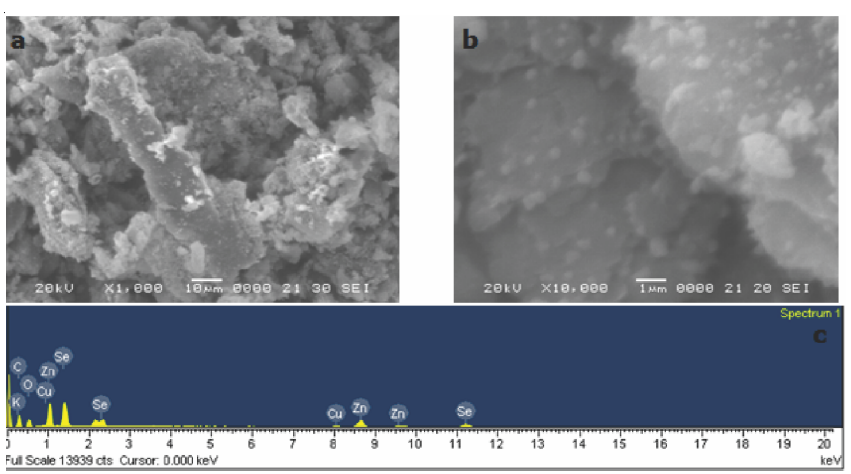

Fig. 2. SEM micrograps of ZnSe/G2 nanocomposites: (a) $1 \mu \mathrm{m}$ (b) $10 \mu \mathrm{m}$ (c) EDX elemental spectra $\mathrm{ZnSe} / \mathrm{G} 2$

between graphene sheet and ZnSe particles. In Fig. 3(b) comparatively another large scale image depicts dispersed nanoparticles on graphene sheet having average particle size $100 \mathrm{~nm}$. Similarly in Fig. 3(c-d) highe magnification image derscribes that during hydrothermal process the crystal growth extends the particle size upto $100 \mathrm{~nm}$ on graphene sheet indicating a small electrostatic interaction between the $\mathrm{ZnSe}$ particles and graphene. Raman spectroscopy is also widely used for the characteristics of the electronic structure of carbon materials. Any change in the Raman band intensity and shifts provide information on the nature of the carbon-carbon bonds and defects ${ }^{17}$. The Raman spectra in Fig. 4 shows the characteristics D and G bands. The D band is the ordinary feature of $s p^{3}$ defects and the $\mathrm{G}$ band provides

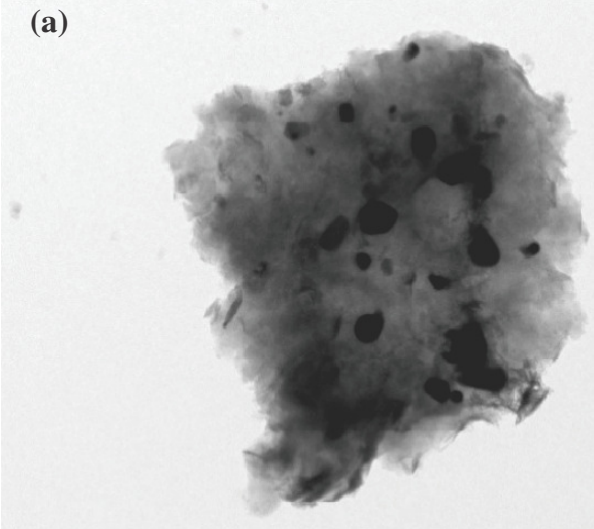

$0.5 \mu \mathrm{m}$

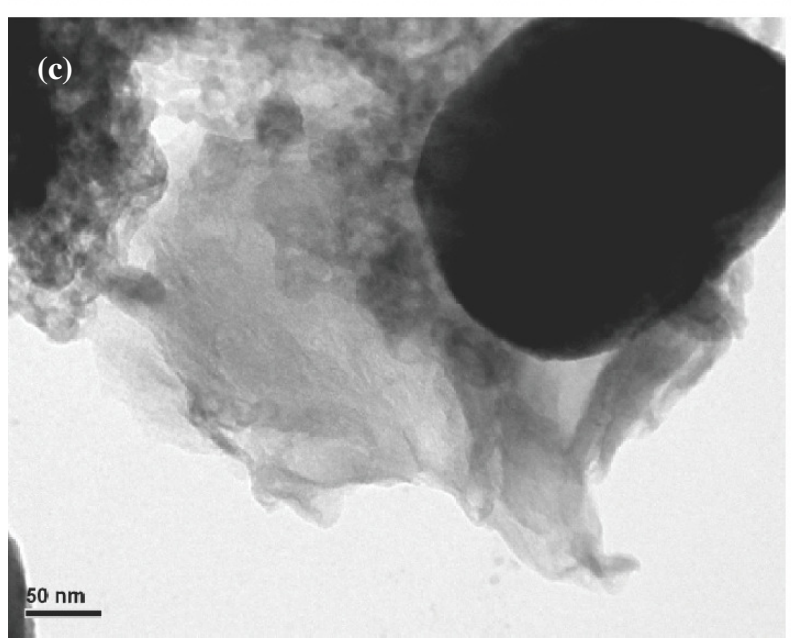

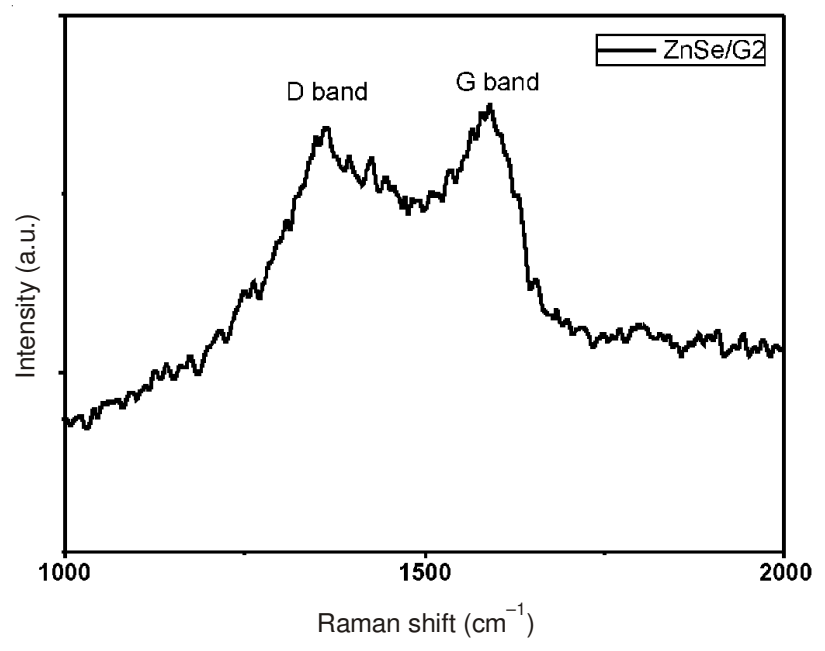

Fig. 4. Raman spectra of ZnSe/G2 nanocomposites

information on in plane vibration of $s p^{2}$ bonded carbons. The intensity ratio of $I_{D}$ to $I_{G}$ reflects the order of defects in graphene oxide or graphene. The calculated $\mathrm{I}_{\mathrm{D}} / \mathrm{I}_{\mathrm{G}}$ ratio of graphene oxide was found to be 1.002 . The $\mathrm{I}_{\mathrm{D}} / \mathrm{I}_{\mathrm{G}}$ ratio indicates the incease in number of graphene layers or partial reduction of graphene oxide into graphene which is consistent with the reports ${ }^{18}$.

Photocatalytic studies: The photocatalytic performance of the $\mathrm{ZnSe} /$ graphene nanocomposites in terms of photo degradation of Methylene orange and Rhodamine-B molecules

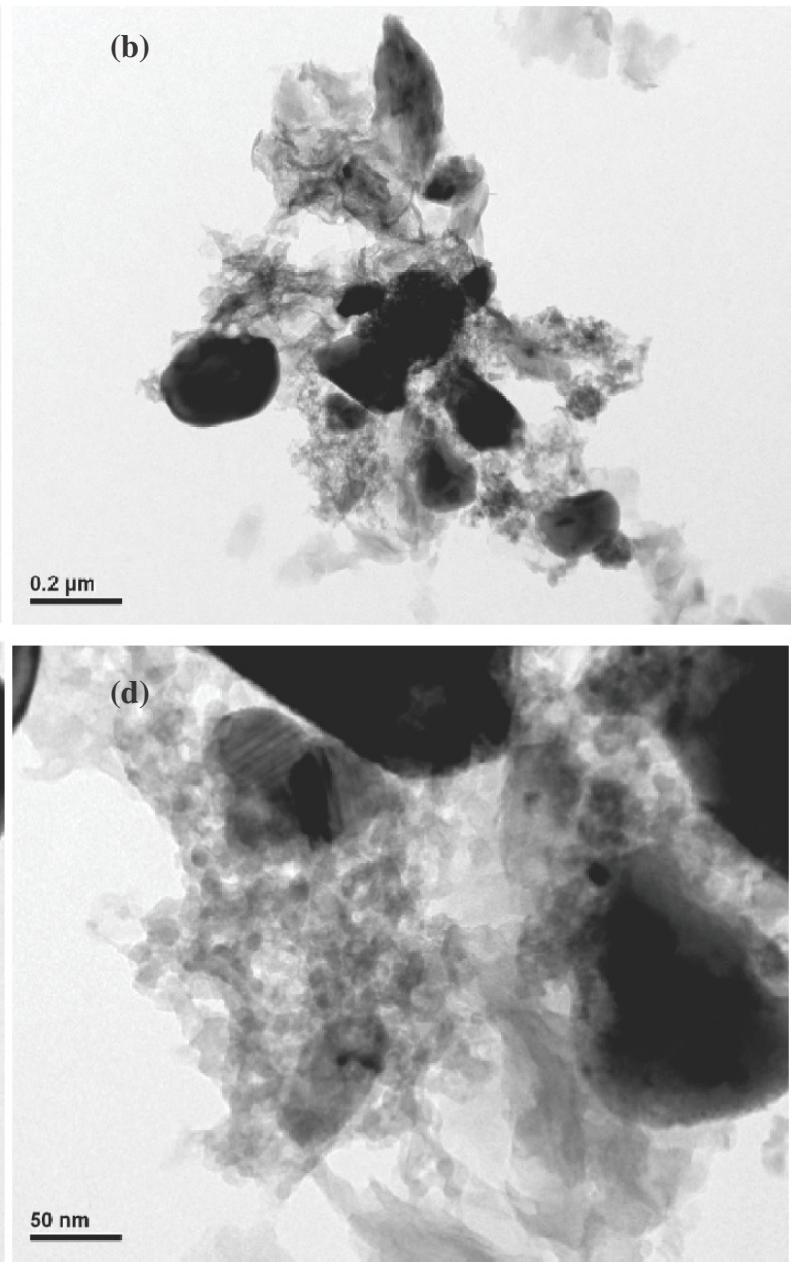

Fig. 3. TEM Images of ZnSe/G2 nanocomposites with different magni-fication 
under visible light irradiation is investigated. Fig. 5(a-b) shows the UV-visible absorption spectra of Methylene orange solution after visible light irradiation for different exposure time in the presence of $\mathrm{ZnSe} / g r a p h e n e$. The characteristic absorption band of Methylene orange solution at $554 \mathrm{~nm}$ is significantly decreased in intensity with increasing irradiation time. Fig. 5(a-b) shows the results of Methylene orange decolourization under visible light irradiation in the presence of $\mathrm{ZnSe} / \mathrm{G} 1$ and $\mathrm{ZnSe} / \mathrm{G} 2$ composites. The normalized temporal concentration change of Methylene orange during the photodegradation process is shown in Fig. 5(c). From Fig. 5(c), maximum degradation is observed for the $\mathrm{ZnSe} / \mathrm{G} 2$ nanocomposites which are attributed to the dispersion of $\mathrm{ZnSe}$ nanoparticles on graphene sheet providing large number of reaction sites. The concentration of Methylene orange in the solution after the photocatalytic degradation reaction was monitored by measuring the absorbance. The kinetic studies were performed on the basis of the degradation rate of the organic dye. The reactions between the dye molecules and the catalyst materials could be expressed by Langmuir- Hinshelwood model ${ }^{19}$. Fig. 5(d) implies that the degradation of Methylene orange follows the pseudo firstorder kinetics expressed as:

$$
-\frac{\mathrm{dC}}{\mathrm{dt}}=\mathrm{K}_{\mathrm{app}} \mathrm{C}
$$

Integration of this equation (with the restriction $\mathrm{C}=\mathrm{C}_{0}$ at $\mathrm{t}=0$, with $\mathrm{C}_{0}$ being the initial concentration in the bulk solution after dark adsorption and $\mathrm{t}$ is the reaction time) will lead to the following relation:

$$
-\ln \frac{\mathrm{C}_{\mathrm{t}}}{\mathrm{C}_{0}}=\mathrm{K}_{\mathrm{app}} \mathrm{t}
$$

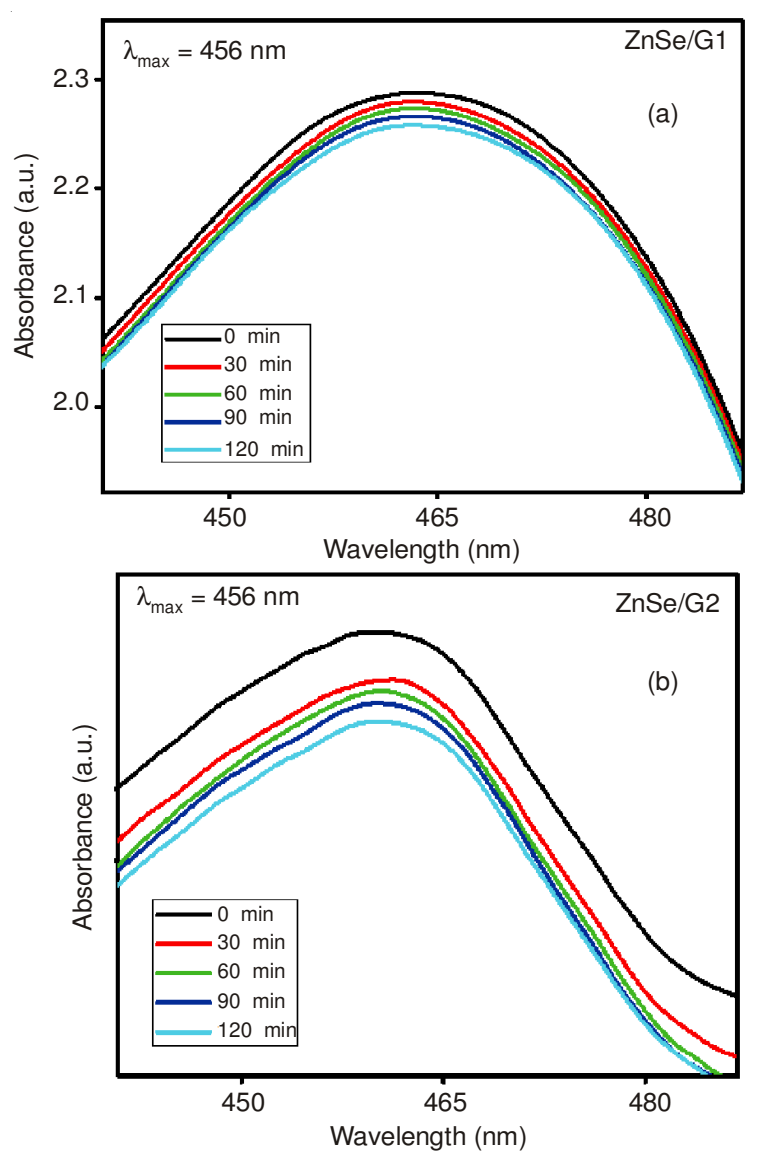

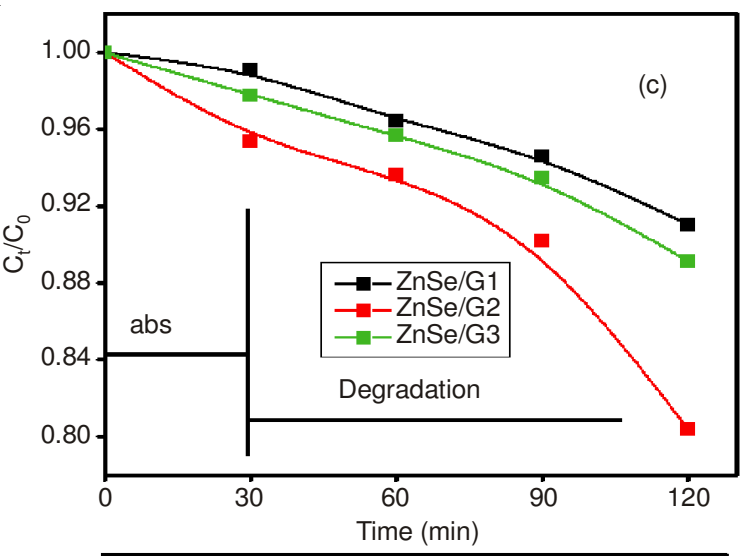

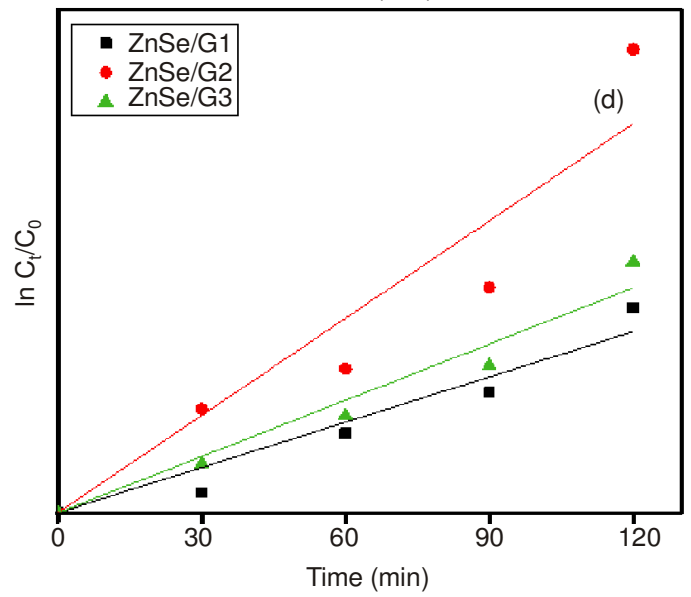

Fig. 5. UV/visible absorption spectra for the Methylene orange degradation by $\mathrm{ZnSe} /$ graphene composites under visible light (a) $\mathrm{ZnSe} / \mathrm{G} 1$ (b) $\mathrm{ZnSe/G2} \mathrm{(c)} \mathrm{Plot} \mathrm{of} \mathrm{Methylene} \mathrm{orange} \mathrm{degradation} \mathrm{efficiency} v s$. irradiation time (d) Apparent pseudo-first order kinetics of Methylene orange degradation over $\mathrm{ZnSe} /$ graphene nanocomposites

where $\mathrm{C}_{\mathrm{t}}$ and $\mathrm{C}_{0}$ are the reactant concentrations at times $\mathrm{t}=\mathrm{t}$, respectively and $\mathrm{K}_{\text {app }}$ and $\mathrm{t}$ are the apparent reaction rate constant and time, respectively. So from the graphical plot in Fig. 5(d) the slope of the linear plots should be equal to apparent first order rate constant $\left(\mathrm{K}_{\text {app }}\right)$. The $\left(\mathrm{K}_{\text {app }}\right)$ values give us the degradation rate of Methylene orange molecules by the photocatalyst materials under the influence of visible light. The Methylene orange degradation rate constant for $\mathrm{ZnSe} / \mathrm{G} 2$ composite were found $\left(1.4 \times 10^{-3}\right) \mathrm{min}^{-1}$ under visible light which are much higher than $\mathrm{ZnSe} / \mathrm{G} 1$ and $\mathrm{ZnSe} / \mathrm{G} 3$ nanocomposites. These results further confirm that $\mathrm{ZnSe} / \mathrm{G} 2$ nanocomposite is much more effective catalyst material than other nanocomposites. The rate constant values are given in Table-1. The photocatalytic activity of the $\mathrm{ZnSe} /$ graphene composite was also observed under the irradiation of visible light using Rhodamine-B as an organic dye. During the catalytic reaction degradation of Rhodamine-B by ZnSe/graphene nanocomposite, most of the Rhodamine-B solution was degraded by the nanocomposite after $2 \mathrm{~h}$ under visible light irradiation as shown in Fig. 6(a-b). The concentration of Rhodamine- $\mathrm{B}\left(\mathrm{C}_{\mathrm{t}}\right.$ and $\mathrm{C}_{0}$ are the concentrations of the organic dye at time $t$ and $t=0$, respectively) in the solution after the photocatalytic degradation reaction was monitored by measuring the absorbance. Fig. 6(c) shows the degradation of Rhodamine-B by the photocatalysis of bare $\mathrm{ZnSe} / \mathrm{G} 1, \mathrm{ZnSe} / \mathrm{G} 2$ and $\mathrm{ZnSe} / \mathrm{G} 3$ nanocomposites. From Fig. 6(c) it is evident that most of the dye molecules are degraded 


\begin{tabular}{|c|c|c|c|c|c|c|c|}
\hline \multicolumn{8}{|c|}{$\begin{array}{l}\text { TABLE-1 } \\
\text { ELEMENTAL WEIGHT }(\%) \text { AND PHOTOCATALYTIC DEGRADATION RATE CONSTANT } \\
\left(\mathrm{K}_{\text {app }}\right) \text { OF ZnSe/GRAPHENE NANOCOMPOSITES UNDER VISIBLE LIGHT }\end{array}$} \\
\hline Samples & $\mathrm{C}(\%)$ & $\mathrm{O}(\%)$ & $\mathrm{Zn}(\%)$ & $\mathrm{Se}(\%)$ & Other $(\%)$ & $\mathrm{K}_{\mathrm{app}}\left(\mathrm{min}^{-1}\right) \mathrm{Rh} . \mathrm{B}$ & $\mathrm{K}_{\mathrm{app}}\left(\mathrm{min}^{-1}\right) \mathrm{MO}$ \\
\hline $\mathrm{ZnSe} / \mathrm{G} 1$ & 60.20 & 16.78 & 15.70 & 6.40 & 0.92 & $7.50 \times 10^{-4}$ & $6.9 \times 10^{4}$ \\
\hline $\mathrm{ZnSe} / \mathrm{G} 2$ & 65.98 & 13.98 & 15.04 & 4.32 & 0.68 & $1.90 \times 10^{-3}$ & $1.4 \times 10^{-3}$ \\
\hline ZnSe/G3 & 75.20 & 8.10 & 12.90 & 3.00 & 0.80 & $9.04 \times 10^{-4}$ & $8.5 \times 10^{-4}$ \\
\hline
\end{tabular}

by $\mathrm{ZnSe} / \mathrm{G} 2$ nanocomposite. The kinetics of the photodegradation for the catalyst was fitted to pseudo first order reaction using Langmiur-Hinshelwood model as shown in Fig. 6(d). The rate constant calculated are listed in Table-1. The above results suggest that the $\mathrm{ZnSe} /$ graphene composites can be used as much more effective photocatalysts. Light irradiation during the photcatalytic experiment after the equillibrium being establish in the dark ambience produces electrons $\left(\mathrm{e}^{-}\right)$in the conduction band (CB) and holes $\left(\mathrm{h}^{+}\right)$in the valence band $(\mathrm{VB})$ of $\mathrm{ZnSe}$ in the composite. Thus a number of electrons $\left(\mathrm{e}^{-}\right)$and holes $\left(\mathrm{h}^{+}\right)$were generated in $\mathrm{ZnSe}$. Meanwhile the electrons in the conduction band of $\mathrm{ZnSe}$ are transferred to the graphene nanosheets, thereby increasing the number of electrons as well as the rate of electron-induced redox reactions. The graphene coupled ZnSe system shows enhanced catalytic activity due to high charge seperation induced by the synergetic effects of graphene and $\mathrm{ZnSe}^{20}$. The generated electrons $\left(\mathrm{e}^{-}\right)$react with dissolved oxygen molecules and produce oxygen peroxide radicals $\mathrm{O}_{2}{ }^{--}$. The positive charge hole $\left(\mathrm{h}^{+}\right)$can react with $\mathrm{OH}^{-}$ derived from $\mathrm{H}_{2} \mathrm{O}$ to form hydroxyl radicals $\mathrm{OH}^{\bullet}$. The Rhodamine- $\mathrm{B}$ and Methylene orange may be degraded by oxygen peroxide radicals $\mathrm{O}_{2}{ }^{--}$and hydroxyl radicals $\mathrm{OH}^{\bullet}$ to $\mathrm{CO}_{2}, \mathrm{H}_{2} \mathrm{O}$ and other mineralization products ${ }^{21,22}$. The reactions involved in the charge mobility and mineralization of the dyes are as follows:
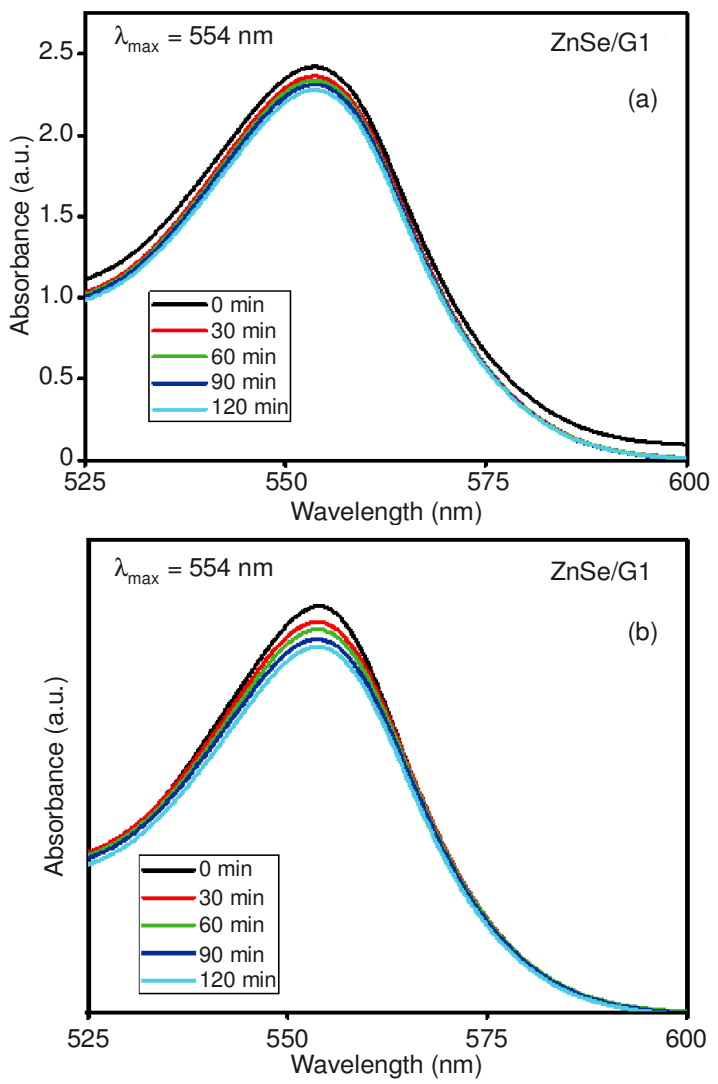
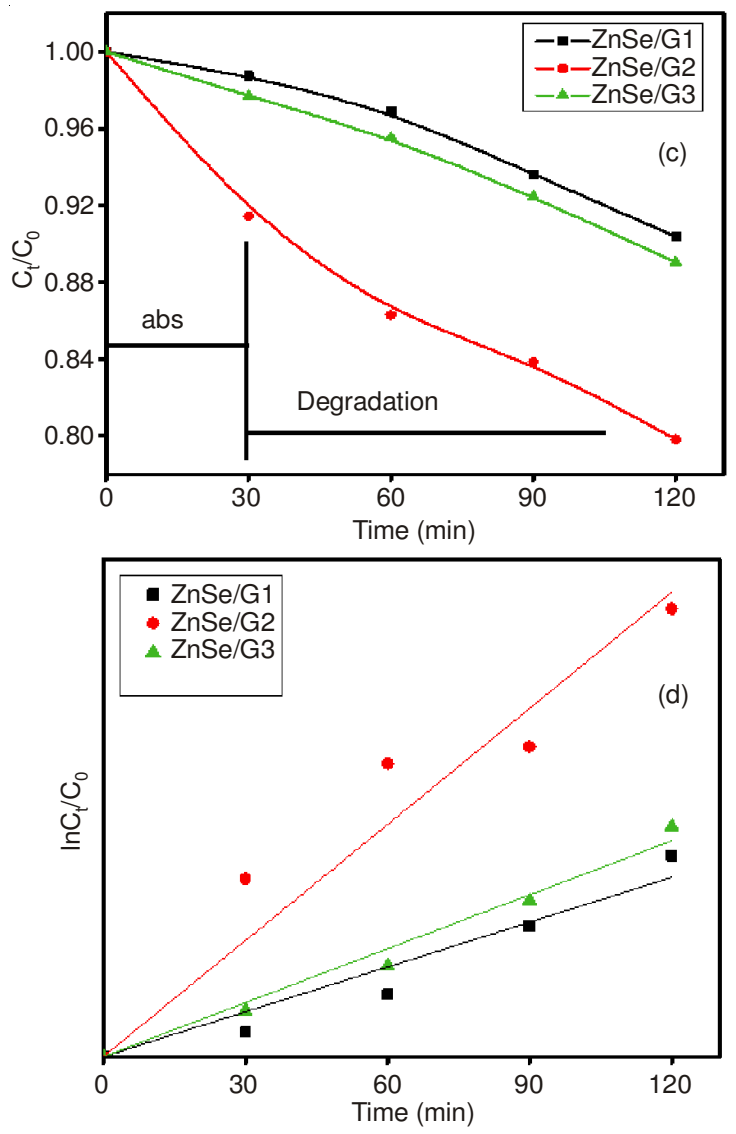

Fig. 6. UV/visible absorption spectra for the Rhodamine-B degradation by $\mathrm{ZnSe} /$ graphene under visible light (a) $\mathrm{ZnSe} / \mathrm{G} 1$ (b) $\mathrm{ZnSe} / \mathrm{G} 2$ (c) Plot of Rhodamine-B degradation efficiency vs. irradiation time (d) Apparent pseudo-first order kinetics of Rhodamine-B degradation over $\mathrm{ZnSe} /$ graphene nanocomposites

$$
\begin{aligned}
& \frac{(\mathrm{h} v) \mathrm{ZnSe}}{\text { Graphene }} \longrightarrow \frac{\mathrm{ZnSe}}{\text { Graphene } \left.^{+} \mathrm{h}^{+}+\mathrm{e}^{-}\right)} \\
& \mathrm{h}^{+}+\mathrm{OH}^{-} \longrightarrow \mathrm{OH}^{\bullet} \\
& \mathrm{O}_{2}+\mathrm{e}^{-} \longrightarrow \mathrm{O}_{2}^{\bullet-} \\
& (\mathrm{MO}, \mathrm{Rh}-\mathrm{B})+\mathrm{OH}^{\bullet}+\mathrm{O}_{2}{ }^{--} \longrightarrow \mathrm{CO}_{2}+\mathrm{H}_{2} \mathrm{O} \\
& + \text { other mineralized by products. }
\end{aligned}
$$

In order to further demonstrate the photo-stability and cyclic performance of the $\mathrm{ZnSe} /$ graphene composite photo-catalyst, cyclic experiments were carried out to degrade Methylene orange and Rhodamine-B as organic dyes. As shown in Fig. 7(a-b), the photo-catalysts did not exhibit any significant loss of photo-catalytic activity after three runs of Methylene orange and Rhodamine-B degradation, which indicates that the $\mathrm{ZnSe} /$ graphene photo-catalyst has high stability and cannot be photocorroded during the photo-catalytic oxidation of the Methylene orange and Rhodamine-B molecules. Thus, the ZnSe/graphene 

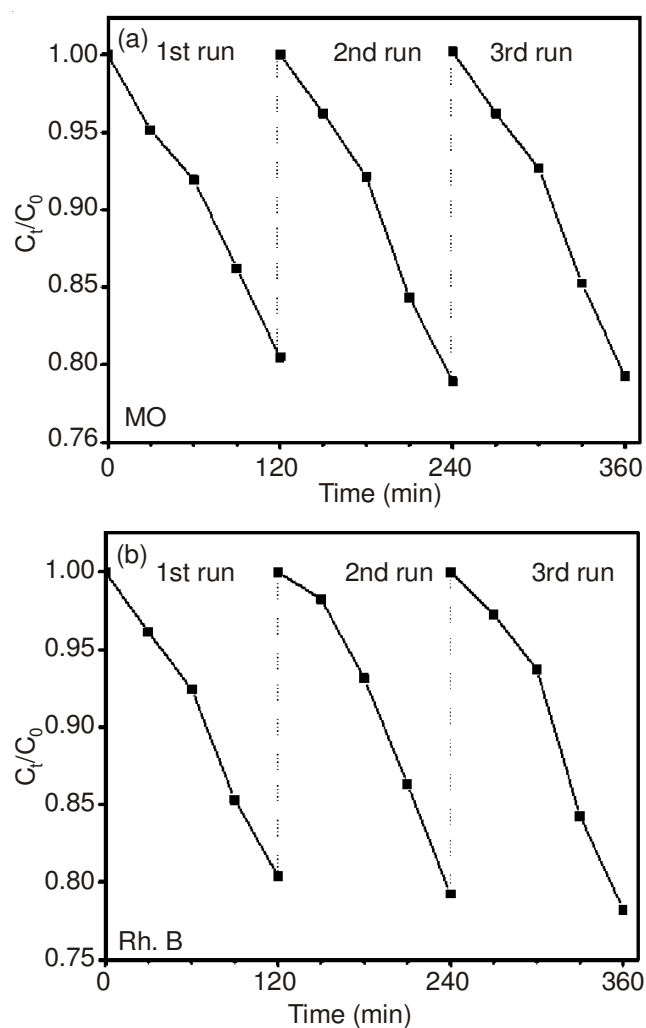

Fig. 7. Degradation efficiency of recycled $\mathrm{ZnSe} /$ graphene photocatalyst over; (a) Methylene orange (b) Rhodamine-B

composite photo-catalyst is promising for practical applications in environmental purification. The reused catalyst does not show any noticeable change in the degradation efficiency which emphasizes the excellent chemical stability of the catalysts that is beneficial for practical application.

\section{Conclusion}

In this study, we successfully synthesized ZnSe/graphene nanocomposite by a facile hydrothermal method. It is clearly observed from the TEM images that $\mathrm{ZnSe}$ /graphene nanocomposite shows relatively good dispersion of nanoparticles on graphene sheet. The structural views of the composites were observed with the SEM images. The XRD pattern of the $\mathrm{ZnSe} /$ graphene nanocomposite suggests all the three composites possessed hexagonal lattice structures. The catalytic activities of $\mathrm{ZnSe} /$ graphene composites were examined by degradation of Methylene orange and Rhodamine-B in aqueous solutions under visible light irradiation. Reused $\mathrm{ZnSe} /$ graphene showed very minute change in degradation efficiency which indicates admirable stability of our photocatalyst materials. This property can prove to be highly beneficial for practical application.

\section{ACKNOWLEDGEMENTS}

This work is supported by research foundation of Hanseo University in 2014. The authors are grateful to the University for financial support.

\section{REFERENCES}

1. X. Li, S. Ouyang, N. Kikugawa and J. Ye, Appl. Catal. A, 334, 51 (2008).

2. N. Mittal, A. Shah, P.B. Punjabi and V.K. Sharma, Rasayan J. Chem., 2, 516 (2009)

3. S. Ameen, M.S. Akhtar, Y.S. Kim, O.B. Yang and H.S. Shin, Colloid Polym. Sci., 288, 1633 (2010).

4. A.K. Geim and K.S. Novoselov, Nat. Mater., 6, 183 (2007).

5. T. Ghosh, K.Y. Cho, K. Ullah, V. Nikam, C.Y. Park, Z.D. Meng and W.C. Oh, J. Ind. Eng. Chem., 19, 797 (2013).

6. T. Ghosh, K. Ullah, V. Nikam, C.-Y. Park, Z.-D. Meng and W.-C. Oh, Ultrason. Sonochem., 20, 768 (2013).

7. Z.Y. Ren, J.Y. Zhang, F.X. Xiao and G.C. Xiao, J. Mater. Chem. A, 2, 5330 (2014).

8. W.C. Oh, K. Ullah, L. Zhu, Z.D. Meng, S. Ye and S. Sarkar, Mater. Sci. Semiconduct. Process., 25, 34 (2014).

9. J. Chu, X. Li and P. Xu, J. Mater. Chem., 21, 11283 (2011).

10. H. Yang, G.H. Guai, C. Guo, Q. Song, S.P. Jiang, Y. Wang, W. Zhang and C.M. Li, J. Phys. Chem. C, 115, 12209 (2011).

11. S.D. Perera, R.G. Mariano, K. Vu, N. Nour, O. Seitz, Y. Chabal and K.J. Balkus Jr., ACS Catalysis, 2, 949 (2012).

12. K. Ullah, Z.D. Meng, S. Ye, L. Zhu and W.C. Oh, J. Ind. Eng. Chem., 20, 1035 (2014).

13. K. Ullah, L. Zhu, Z.-D. Meng, S. Ye, Q. Sun and W.-C. Oh, Chem. Eng. J., 231, 76 (2013).

14. T. Ghosh, J.-H. Lee, Z.-D. Meng, K. Ullah, C.-Y. Park, V. Nikam and W.-C. Oh, Mater. Res. Bull., 48, 1268 (2013).

15. Z.D. Meng, L. Zhu, T. Ghosh, C.-Y. Park, K. Ullah, V. Nikam and W.C. Oh, Bull. Korean Chem. Soc., 33, 3761 (2012).

16. K. Ullah, S. Ye, L. Zhu, Z.-D. Meng, S. Sarkar and W.-C. Oh, Mater. Sci. Eng. B, 180, 20 (2014).

17. R. Rao, R. Podila, R. Tsuchikawa, J. Katoch, D. Tishler, A.M. Rao and M. Ishigami, ACS Nano, 5, 1594 (2011).

18. K. Kudin, B. Ozbas, H.C. Schniepp, R.K. Prud'homme, I.A. Aksay and R. Car, Nano Lett., 8, 36 (2008).

19. Y. Yokomizo, S. Krishnamurthy and P.V. Kamat, Catal. Today, 199, 36 (2013).

20. Y. Yu, L.L. Ma, W.Y. Huang, F.P. Du, J.C. Yu, J.G. Yu, J.-B. Wang and P.-K. Wong, Carbon, 43, 670 (2005).

21. C. Deng, H. Hu, X. Ge, C. Han, D. Zhao and G. Shao, Ultrason. Sonochem., 18, 932 (2011).

22. A.Z. Abdullah and P.Y. Ling, J. Hazard. Mater., 173, 159 (2010). 